\title{
White Electroluminescence from Bicarbazyl-containing Conjugated Polymers as Single-Emitting Component
}

\author{
In-Nam Kang, ${ }^{\dagger}$ Yang-Bae Kim, ${ }^{\ddagger}$ Sung-Hwan Lim, Min-Chul Chung, \\ Se-Young Oh," Sung-Ryong Kim, and Ji-Hoon Lee* \\ Functional Ifaterials Lab., Department of Polymer Science and Engineering, Chungin National Chiversity, \\ Chunglu 380-702, Korea. ${ }^{*}$ E-mail: jihoonliacinuackr \\ - Department of Chemistry The Catholic Lniversity of Korea, Bucheon $+20-743$, Korea \\ Institute of Photonics \& Surface Treatment, O-s7s Co., Ltd., Gwangiu 500-460, Korea

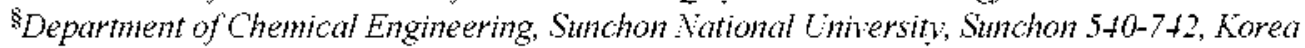 \\ ${ }^{*}$ Deparment of Chemical \& Biomolectlar Engineering Interdisciplinary Program of Integrated Biotechnologv: \\ Sogang Lnversity Seoul 121-7+2, Korea \\ Received September 20,2007
}

\begin{abstract}
Two bicarbazyl-containing fluorene copolymers. PFEBCz (95/5) and $\mathrm{PFEBCz}(75 / 25)$. were synthesized for white light electroluminescence from a single emitting polymer. All syynthesized polymers were soluble in common organic solvents such as chloroform and toluene. The weight-average molecular weights $\left(\mathrm{M}_{w}\right)$ of the $\mathrm{PFEBCz}(95 / 5)$ and PFEBCz (75/25) copolymers were found to be 11.000 and 5.700 with polydispersity indices 1.4 and 1.8 . The EL spectnum of the $\mathrm{PFEBCz}(75 / 25)$ device showed bright white-light emission with CIE coordinates of $(0.32,0.34)$ at $1000 \mathrm{~cd} / \mathrm{m}^{2}$. which is very close to that for pure white $(0.33,0.33)$. This white emission may have been due to strong excimer formation between the bicarbazy'l and fluorene polymer backbone. The device exhibited a maximum brightness of $3400 \mathrm{~cd} / \mathrm{m}^{2}$ with a maximum efficiency of $0.2 \mathrm{~cd} / \mathrm{A}$.
\end{abstract}

Key Words : White emitting, Bicarbazyl, Excimer, Single-emitting

\section{Introduction}

The potential for making large-area multicolor displays from easily processible polymers has driven much of the recent research in the area of polymer light-emitting diodes (PLEDs). Recently: white PLEDs (WPLEDs) have received particular attention because of their potential applications in backlight and full color display's with color filters. ${ }^{1-12}$ One of main approaches to producing WPLEDs is to use a polymer blend system. such as three-polymer blends containing red. green and blue polymers. ${ }^{13}$ and blends consisting of two or three kinds of fluorescent dyes in an efficient blue-emitting polymer matrix. ${ }^{14.15}$ However. it is difficult to obtain highly' efficient and color stable WPLEDs using polymer blend sy'stems due to undesirable Forster-ty'pe energy transfer between chromophores. Another approach is to use single layer devices made from homopolymers ${ }^{16.17}$ or copolymers. ${ }^{18-30}$ However. the devices constructed to date according to this approach have not shown ideal CIE (Commission International de l'Eclairage) coordinates for white light emission (0.33, 0.33) and color stability. Therefore. new polymer materials are needed that are better suited to these singlelayer devices. Here we report on efficient single emitting component WPLEDs with a single-layer structure fabricated from poly [9.9'-bis(2'-ethy lhexyl)fluorene-2.7-diyl-co- $N N^{\prime}$ diethỵl-3.3'-bicarbazyl-6,6'-diỵl]. copolymers (PFEBCzs).

\section{Experimental Section}

\section{Synthesis of Monomers}

Synthesis of N,N'-Diethyl-3,3'-bicarbazyl (1): To a solution of $N$-ethylcarbazole $(20 \mathrm{~g} .99 .35 \mathrm{mmol})$ in chloroform $(150 \mathrm{~mL}) . \mathrm{FeCl}_{3}(64.46 \mathrm{~g} 0.397 \mathrm{~mol})$ was added dropwise At this point. the reaction mixture gradually turned to dark green color due to the formation of carbazole cation radicals. After 24 hours. the reaction mixture was poured into an excess of methanol. The precipitated solids were isolated by filtration and continuously washed with excess methanol and three times with water. After dried, the title compound was obtained at $95 \%$ yield. ${ }^{1} \mathrm{H}-\mathrm{NMR}(300 \mathrm{MHz}, \mathrm{CDCl}$ ) $: \delta$ 1.50 (t. $6 \mathrm{H}, 2-\mathrm{CH}_{3}$ ). 4.45 (quartet, $4 \mathrm{H}, 2-\mathrm{NCH}_{2}$ ). 7.26-8.5 (m. $14 \mathrm{H}$, aromatic protons).

Synthesis of $\mathrm{N}, \mathrm{N}^{\prime}$-Diethyl-6,6'-dibromo-3,3'-bicarbazyl (2): Compound (1) $(4 \mathrm{~g} .10 \mathrm{mmol})$ was put into a $100 \mathrm{~mL}$ Schlenk flask and $50 \mathrm{~mL}$ of chloroform was added to dissolve the contents. Separately bromine $(5.0 \mathrm{~g} .31 \mathrm{mmol})$ was dissolved in $10 \mathrm{~mL}$ of chloroform. The resulting solution was added to the flask dropwise. The reaction temperature was kept at $0{ }^{\circ} \mathrm{C}$ using an ice bath. After 40 minutes. the reaction mixture was poured into an excess of water and washed with $1.0 \mathrm{~N} \mathrm{NaOH}(\mathrm{aq})$. The reaction mixture was dissolved in chloroform $(250 \mathrm{~mL})$ and again poured into an excess of methanol. The precipitated solids were isolated by filtration and washed repeatedly with excess methanol and water. After drying. the crude product was purified by column chromatography using a cosolvent ( $n$-hexane/chloroform $=3 / 1$ ) as the eluent. Finally, the title compound was obtained at $90 \%$ yield $(4.92 \mathrm{~g})$. ${ }^{\mathrm{l}} \mathrm{H}-\mathrm{NMR}$ $\left(300 \mathrm{MHz} . \mathrm{CDCl}_{3}\right): \delta 1.46\left(\right.$ t. $\left.6 \mathrm{H}, 2-\mathrm{CH}_{3}\right) .4 .34$ (quartet. $4 \mathrm{H}$. 2-NCH$\left.{ }_{2}\right), 7.26-8.33$ (m. 12H. aromatic protons): ${ }^{13} \mathrm{C}-\mathrm{NMR}$ 
$\left(75 \mathrm{MHz}_{2} \mathrm{CDCl}_{3}\right): \delta 139.3 .139 .0 .133 .5,128.36,126.2$. 124.8. 123.3. 122.5, 119.1, 111.6. 110.0, 109.0, 37.8, 13.8: $\mathrm{Fab}^{+}$-Mass me 5+6.3.

Synthesis of 2,7-Dibromo-9,9'-dioctylfluorene (3). was prepared according to a previously reported method. ${ }^{21}$

${ }^{1} \mathrm{H}-\mathrm{NMR}\left(300 \mathrm{MHz}, \mathrm{CDCl}_{3}\right): \delta 0.60(\mathrm{~m}, 4 \mathrm{H}), 0.83(\mathrm{t}, 6 \mathrm{H}$. 2- $\left.\mathrm{CH}_{3}\right) .1 .29-1.07$ (n. 20H). $1.96(\mathrm{~m} .4 \mathrm{H}) 7.28-7.55(\mathrm{~m}, 6 \mathrm{H}$. aromatic protons).

General Procedure for Polymerization. Two bicarbazy lcontaining copolymers PFEBCz $(95 / 5)$ and $\mathrm{PFEBC} z(75 / 25)$ were synthesized by nickel $(0)$-mediated polymerization. The feed ratio of bicarbazyl monomer was 5 and $25 \mathrm{~mol} \%$ of total amount of polymer, and the total amount of reactants was ranged from 1.6 to $1.8 \mathrm{mmmol}$. Each $100 \mathrm{~mL}$ Schlenk flask containing anthydrous DMF $(5 \mathrm{~mL})$. bis $(1,5$-cyclooctadienyl) nickel( $(0)$. 2,2'-dipyridyl and 1.5 -cyclooctadiene (the last three in a molar ratio of $1: 1: 1$ ) was kept under nitrogen atmosphere at $78{ }^{\circ} \mathrm{C}$ for $15 \mathrm{~min}$. Reactants dissolved in anhydrous toluene $(15 \mathrm{~mL})$ were added to the nixture. The polymerization was maintained at $78^{\circ} \mathrm{C}$ for $36 \mathrm{~h}$, and then $0.5 \mathrm{~mL}$ of bromopentafluorobenzene was added to reaction mixture for end-capping reaction. When the reaction had finished. each polymer was precipitated from an equivolume mixture of $\mathrm{HCl}$. methanol and acetone. The polymers were dissolved in small amount of toluene and precipitated in methanol. The resulting polymers were purified with column chromatography using toluene as the eluent. Finally. the resulting polymers were further purified by Soxhlet extraction using methanol and then dried in vacuum. The polymer yields ranged from 30 to $40 \%$ after purification

PFEBCz (95/5): ${ }^{1} \mathrm{H}-\mathrm{NMR}\left(300 \mathrm{MHz}, \mathrm{CDCl}_{3}\right): \delta 0.73$ (n. $\left.\mathrm{N}-\mathrm{CH}_{2}-\mathrm{CH}_{3}\right), 0.86\left(\mathrm{~m},-\mathrm{CH}_{2}-\right.$ of dioctylfluorene), $1.56-1.13$ (m, - $\mathrm{CH}_{2}=$ of dioctylfluorene), 2.17 (nl. $-\mathrm{CH}_{2}-$ of dioctylfluorene), 4.48 (m. N-CHz-), 7.56-7.99 and 8.55 (aromatic protons). FT-IR (KBr. $\mathrm{cm}^{-1}$ ): 3055 (aromatic C.H). 2955 2855 (aliphatic C-H). 2000-1670 (multi-substituted combination). 1605,1459 (aromatic $\mathrm{C}=\mathrm{C}$ ), $1230(\mathrm{C}-\mathrm{N}), 877.814$ (1.2.4-subsituted out-of-plain $\mathrm{C}-\mathrm{H}$ bending).

Instruments. ${ }^{1} \mathrm{H}$ and ${ }^{13} \mathrm{C}$ NMR spectra were recorded using a Bruker Avance-400 spectrometer. The absorption spectra were measured using a Hitachi spectrophotometer model U-3501 and the steady-state PL spectra were recorded on a Spex FL3-11. The molecular weights of the polymers were determined by gel permeation chromatography (GPC) analysis relative to a polystyrene standard using a Waters high-pressure GPC assembly Model M590. Thermal analyses were carried out on a DuPont TGA 9900 thermogravimetric analyzer under a nitrogen atmosphere at a heating rate of $10^{\circ} \mathrm{C} / \mathrm{min}$. Cyclic voltanmograms $(\mathrm{CV})$ of the polymer films (dip-coated onto $\mathrm{Pt}$ wire) were recorded on an AUTOLAB/PGSTAT 12 at room temperature in a solution of tetrabutylammonium hexafluorophosphate $\left(n-\mathrm{Bu}_{4} \mathrm{NPF}_{6}\right)$ $(0.1 \mathrm{M})$ in acetonitrile under nitrogen gas protection at a scan rate of $100 \mathrm{mV} / \mathrm{s}$. For the measurement of EL device characteristics. current-roltage (I-V) changes were obtained using a current/soltage source (Keithley 238) and an optical power meter (Newport 818-SL). The brightness and 1931
CIE chromaticity of each EL device were recorded with a PR-650 SpectraScan colorimeter.

Fabrication of the Light-Emitting Diodes. Each polymer film was prepared by spin casting a blend solution containing $1 \%$ of the polymer by weight in toluene. Uniform and pinhole free films with a thickness around $100 \mathrm{~nm}$ were easily obtained from the polymer solutions. For the double layer device, a modified water dispersion of PEDOT [poly(3.4-ethylenedioxy-thiophene)] doped with poly(styrene sulfonate) (PSS) (Bayer AG Germany) was used as the holeinjection/transport layer. A metal contact ( $\mathrm{Ca}$ ) was deposited on top of the polymer film through a mask by vacuum evaporation at a pressure below $4 \times 10^{-6}$ torr, yielding active areas of $4 \mathrm{~mm}^{2}$. In the case of the Ca cathode $(-50 \mathrm{~nm})$, an additional encapsulating layer of $\mathrm{Al}(-200 \mathrm{~nm})$ was thermally evaporated onto it. All processes and measurements mentioned above were carried out in nitrogen atmosphere with glass encapsulation at room temperature.

\section{Results and Discussion}

Scheme 1 shows an overview of the synthesis of the monomer and polymers. The copolymers were synthesized using the $\mathrm{Ni}(0)$-mediated coupling reaction. All synthesized polymers were soluble in common organic solvents such as chloroform and toluene without evidence of gel formation. The weight-average molecular weights $\left(\mathrm{M}_{*}\right)$ of the $\mathrm{PFEBCz}$ $(95 / 5)$ and PFEBCz (75/25) copolymers were found to be
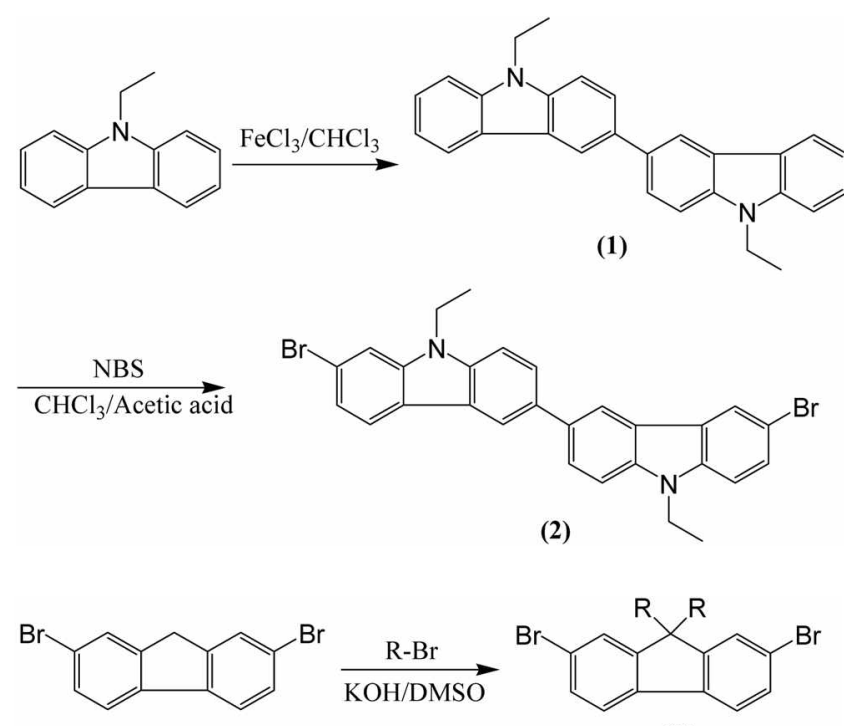

(3)

m(2) $+\mathbf{n}$ (3) $\stackrel{\mathrm{Ni}(\mathrm{COD})_{2}}{\longrightarrow}$

( $R=$ 2-Ethylhexyl)

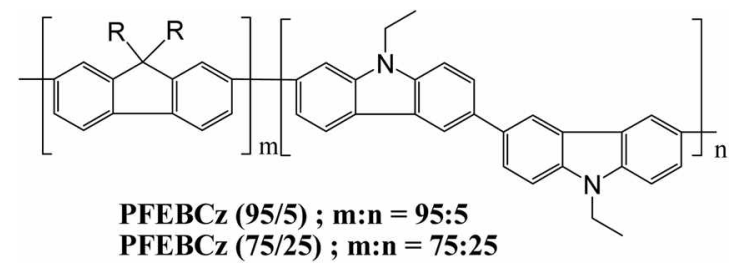

Scheme 1. Synthetic routes for PFEBCz copolymers. 
Table 1. Sunnnary of the characteristics of the synthesized polymers

\begin{tabular}{|c|c|c|c|c|c|c|}
\hline & $\begin{array}{c}\text { Feed ratios of } \mathrm{BCz} \\
(\text { mole } \%)\end{array}$ & $\begin{array}{c}\text { Autual ratios of } \mathrm{BCz} \\
\text { (mole \% })^{*}\end{array}$ & $\mathrm{M}_{\mathrm{n}}$ & $\mathrm{M}_{w}$ & PDI & $\begin{array}{c}\text { Polymer y ield } \\
(\%)\end{array}$ \\
\hline $\mathrm{PFEBCz}(95 / 5)$ & 5 & 4.5 & 8,000 & 11,000 & 1.4 & 40 \\
\hline $\mathrm{PFEBCz}(75 / 25)$ & 25 & 23.9 & 3,100 & 5,700 & 1.8 & 35 \\
\hline
\end{tabular}

"Determined by ' $\mathrm{H}-\mathrm{NMR}$ integration of $-\mathrm{NCH}_{2}$ protons of $\mathrm{BCz}$ 's. methylene $\left(-\mathrm{CH}_{2}-\right)$ protons of the fluorene moiety.

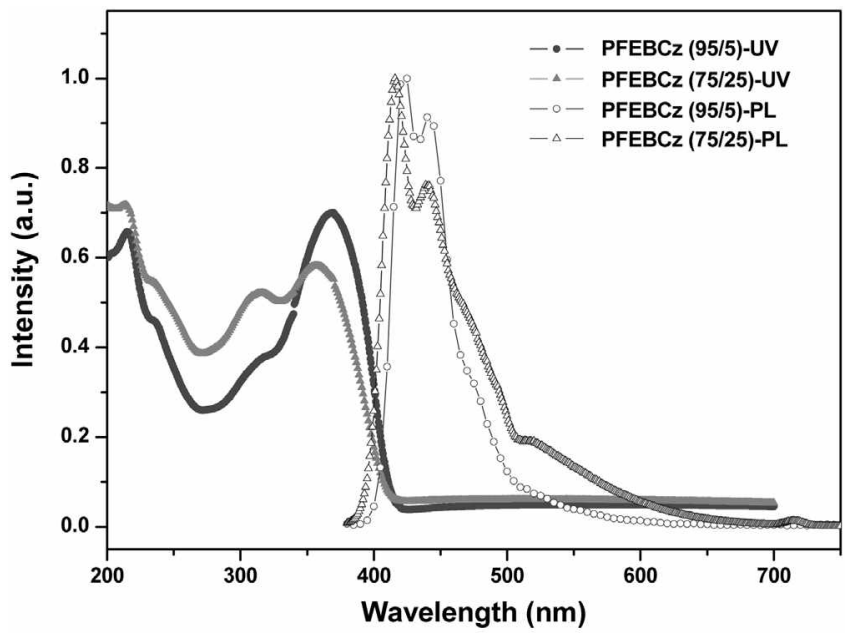

Figure 1. UV-visible absorption and PL emission spectra of the polymer films.

11.000 and 5.700 with polydispersity indices 1.4 and 1.8 . using gel permeation cluronatography (GPC) with a polystyrene standard. The polymer yields were around $40 \%$ after purification. The actual ratios of the monomers within the copolymers were deternined using the ${ }^{1} \mathrm{H}-\mathrm{NMR}$ method. The results for the synthesized polymers are summarized in Table 1.

Figure 1 shows the normalized UV-visible absorption and photoluminescence (PL) spectra of thin films of the polymers coated onto fused quartz plates. Both films exhibit absorption maxima at around $360 \mathrm{rm}$ and a weak absorption peak at $310 \mathrm{~nm}$. The main peak is consistent with that reported for the fluorene homopolymer. ${ }^{6}$ The relative ratio of the absorbances. $310 / 360 \mathrm{~nm}$. was found to increase as the fraction of bicarbazyl units $(\mathrm{BCz})$ in the polymer increased. indicating that the weak absorptions at $310 \mathrm{~nm}$ result from the $\mathrm{BCz}$ unit. When the PFEBCz (75/25) and PFEBCz (95/ 5) polymers are excited at their absorption maximum, their PL emission peaks appear at round $420 \mathrm{~nm}$ with shoulder peaks at round 470 and $530 \mathrm{~mm}$. respectively: The PL intensity of the longer wavelength emission at around $530 \mathrm{~nm}$ of the PFEBCz $(75 / 25)$ film is slightly greater than that of the $\mathrm{PFEBCz}(95 / 5)$ film. indicating that excimer formation is enhanced by increasing the proportion of $\mathrm{BCz}$ units in the copolymer.

To investigate the EL properties of the polymers. EL devices were fabricated with the configuration ITO/PEDOT $(25 \mathrm{~nm}) /$ polymer $(100 \mathrm{~nm}) / \mathrm{Ca}(50 \mathrm{~nm}) / \mathrm{Al}(200 \mathrm{~mm})$. The EL spectrum of $\mathrm{PFEBCz}(75 / 25)$ shows white emission consisting of two emission peaks. at 420 and $540 \mathrm{~nm}$. with tailing

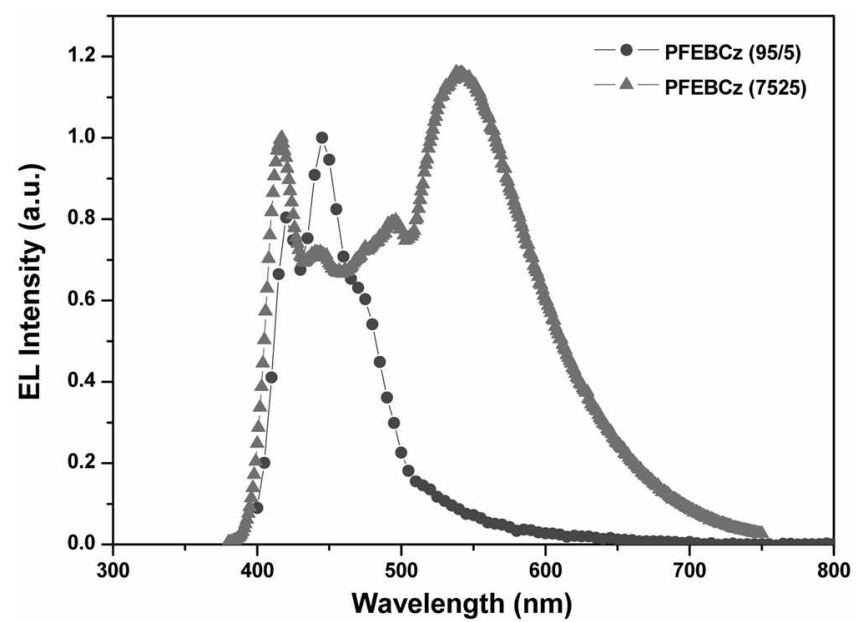

Figure 2. EL spectra of the EL devices with ITO/PEDOT/polymer/ $\mathrm{Ca} / \mathrm{Al}$ configuration.

of the longer wavelength (see Figure 2). The CIE coordinates of this device were $(0.32,0.34)$, which is very close to those of standard white emission. $(0.33$. 0.33). For the $\mathrm{PFEBCZ}(95 / 5)$ device, however. the emission peak was at $440 \mathrm{~nm}$, in the blue region. and the CIE coordinates were $(0.17,0.16)$ at $1000 \mathrm{~cd} / \mathrm{m}^{2}$. The blue emission from this device can be attributed to the low bicarbazyl content of the copolymer used. The above results therefore strongly suggest that the main peak and shoulder peak in the PL spectrum, and their corresponding peaks in the EL spectrum. can be assigned to emissions of the lumophore and excimer.

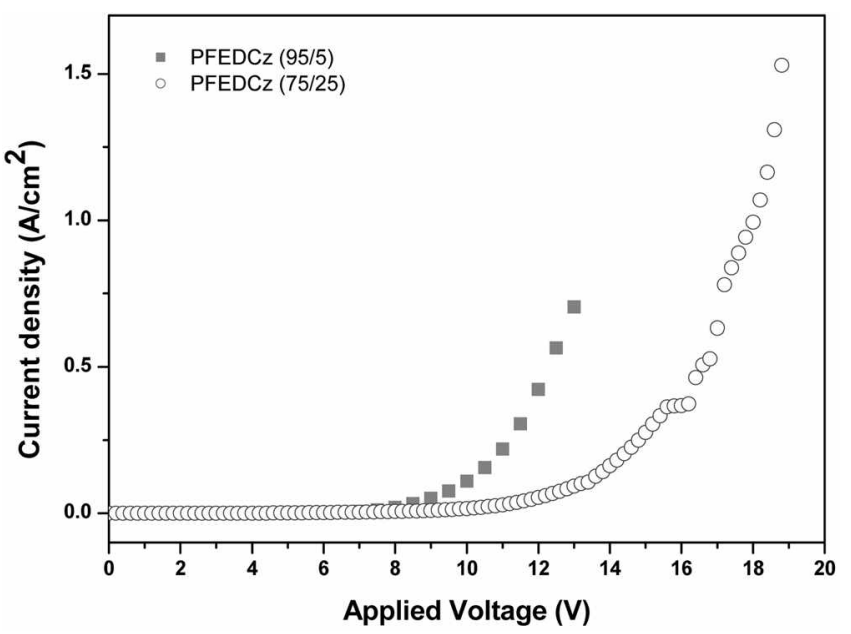

Figure 3. Plot of the current density as function of the applied voltage for the EL devices with ITO/PEDOT/polymer/Ca/Al configuration. 


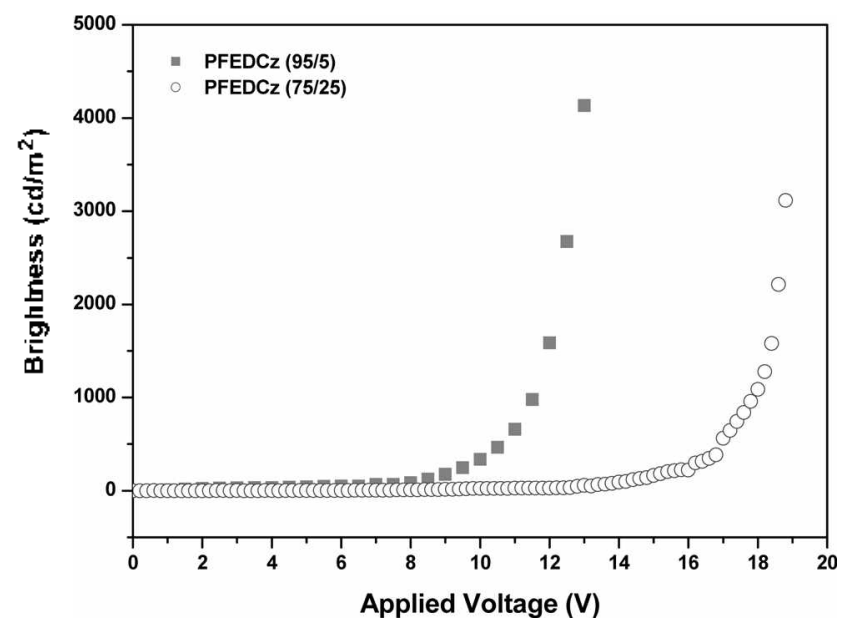

Figure 4. Plot of the luminescence as function of the applied voltage for the $\mathrm{EL}$ devices with $\mathrm{ITO} / \mathrm{PEDOT} / \mathrm{polymer} / \mathrm{Ca} / \mathrm{Al}$ configuration.

respectively. The longer wavelength enission of $\mathrm{PFEBCz}$ $(75 / 25)$ results from excimer formation by the bicarbazyl units, which increased as the fraction of bicarbazyl units in the polymer increased. This excimer emission may be due to enhanced charge separation along the conjugated segment induced by the incorporation of the electron donating bicarbazyl group. The devices made from $\mathrm{PFEBCz}(95 / 5)$ and PFEBCz (75/25) exhibited maximum brightnesses of 6000 and $3400 \mathrm{~cd} / \mathrm{m}^{2}$ with maximum efficiencies of 0.7 and 0.2 $\mathrm{cd} / \mathrm{A}$. respectively (see Figure 3 and 4 ).

To test the color stability of the white light enitted from a single polymer, the EL spectra of the $\mathrm{PFEBCz}(75 / 25)$ device were measured at brightnesses of 100 and $1000 \mathrm{~cd} /$ $\mathrm{m}^{2}$. The EL spectrum was only slightly different at these brightmesses. The $\mathrm{ClE}$ coordinates at the brightnesses of 100 and $1000 \mathrm{~cd} / \mathrm{m}^{2}$ were $(0.27 .0 .34)$ and $(0.32 .0 .34)$. respectively. corresponding to applied voltages of 13.2 and $18 \mathrm{~V}$. respectively. However. it is worthwhile to note that the bicarbazyl gave strong excimer formation in the fluorene poly'mer backbone.

\section{Conclusion}

In summary. we have sucessfully developed a white-light emitting device based on a single polymer. the bicarbazylcontaining fluorene copolymer $\mathrm{PFEBCz}(75 / 25)$. The $\mathrm{EL}$ spectrum of this device shows white-light emission with CIE coordinates of $(0.32 .0 .34)$ at $1000 \mathrm{~cd} / \mathrm{m}^{2}$. The white-light emission of this device may be due to excimer formation between the bicarbazyl and fluorene polymer backbone Further investigation along these lines is in progress.

Acknowledgements. This work was supported by the Ministry of Commerce. Industry and Energy (MOCIE) through the project of Regional Research Center (RRC) at Sunchon National University. Also, this work was supported by grant No. R01-2006-00010196-0 from the Basic Research Program of the Korea Science \& Engineering Foundation

\section{References}

1. Xu. Q. F.: Duong. H. M.: Wudl. F.: Yang. Y. Appl. Phusic. Lett 2004. 85.3357 .

2. Gong. X: Ma. W. L.: Ostrowski. T. C.: Bazan. G. C.: Moses. D. Heeger. A. J. Adv Mater 2004. 16.615.

3. Jin. S. H.: Jang, M. S.: Suh. H. S.: Cho. H. N.: Lee. J. H.: Gal. Y. S. Chem. Hater 2002. 14.643.

4. Huang. J.: Li. K.: Wu. E.: Xu. Q: Yang. Y. Adt: Mater: 2006. 18. 114.

5. Wu. F. I.: Yang. X. H.: Neher. D.: Dodda. R.: Tseng. Y. H.: Shu. C. F. Adv Funt Hater: 2007. 17, 1085.

6. Wu, W. C.: Lee, W. Y. Chen, W. C. Macromol Chem. Phys. 2006. 207. 1131 .

7. Jin. Y. E.: Kim. S. H.: Song. S. H.: Kim. T. W.: Kim. T. H.: Hark. S. H.: Lee. K. H.: Sulh. H. S. Bull. Korean Chem. Soc. 2006. 27(7). 1043 .

8. Sun. M.: Niu. Q: Du, B.: Peng. J.: Yang. W.: Cao. Y. Macromol. Chem. Phs. 2007, 208.988.

9. Jin, Y. E.: Kim. S. H.; Lee, H. J.: Song. S. H; Kim, Y. N.: Woo, H Y.: Lee. K. H.: Suh. H. S. Bull. Korem Chent Soc. 2007. 28(12). 2293

10. Luo. J.: Li. X: Hou. Q: Feng. T: Yang. W.: Cao. Y. Ad: Mater. 2007. 19, 1113

11. Liu. J:: Xie, Z.: Cheng, Y; Geng. Y.: Wang. L.; Jing. X: Wang, F. Adn Hater: 2007.19,531.

12. Liu. X.: Guo. X.: Bu. L.: Xie. Z.: Cheng. Y.: Geng. Y.: Wan1g. L.: Jing. X.: Wang. F. Adr: Funct. Mater 2007. 17. 1917.

13. Granstrom. M.: Inganas. O. Appt Phs Lett. 1996. 68. 147.

14. Furuta. P. T.; Deng, L: Garon. S.: Thompson, M. E.: Frechet, J. M. J. J.Am. Chem. Soc, 2004, 126, 15388

15. Kim. J. H.; Herguth, P. M.: Kang. S.: Jen. A. K. Y: Tseng. Y. H: Shu. C. F. Appl. Phns. Lett. 2004. 85.1116.

16. Yan1g. Y. : Pei. Q. Appl. Phns. Lett. 1997. 81. 3294

17. Tsai. M. L.: Liu. C. Y.: Hsu. M. A.: Chow. T. T. Appl. Phns. Lett. 2003. 82,550

18. Liu. J.: Zhou. Q.: Cheng, Y:; Geng, Y.: Wang, L.; Ma, D.; Jng, X: Wang, F. Adv 1 Iater 2005, 17,2974.

19. Lee. S. K.: Hwang. D. H.: Tung. B. T.: Cho. N. S.: Lee. T. D. Shim. H. K. Adt: Funct. Hater 2005. 15. 1647.

20. Cha. S. W. Tin. J. J. J. Mater Chen 2003. 13. 479

21. Inbasekaran, M: Wu. W. Woo, E. P. US Patent $5.777,070$ to Dow Company, 1998.

22. Hyun. A. R.: Lee. J. H.: Kang, I. N.: Park, J. W. Thin Solid Films 2006. 209. 127. 